\title{
Christopher POLLIT y Geert BOUCKAERT. PUBLIC MANAGEMENT REFORM. A Comparative Analysis into the Age of Austerity, 4. ${ }^{a}$ edición, Oxford University Press, Oxford, 2017
}

\section{Christopher POLLIT \& Geert BOUCKAERT. PUBLIC MANAGEMENT REFORM. A Comparative Analysis into the Age of Austerity. 4th edition. Oxford University Press, Oxford, 2017}

\author{
Miguel Anxo Bastos Boubeta \\ Universidade de Santiago de Compostela \\ mbastos@ufm.edu
}

\begin{abstract}
NOTA BIOGRÁFICA
Miguel Anxo Bastos Boubeta es profesor titular del Departamento de Ciencia Política y de la Administración de la Universidad de Santiago de Compostela, licenciado en Ciencias Económicas y doctor en Ciencias Económicas y Empresariales por la Universidad de Santiago de Compostela, además de licenciado en Ciencias Políticas por la UNED. Es autor de monografías, artículos de investigación especializados y recensiones publicados en las principales revistas académicas de su especialidad.
\end{abstract}

Los casi diez años que duró la gran crisis de 2007 no parecen haber sido años de grandes reformas en el ámbito de la administración pública ni años de grandes innovaciones técnicas o ideológicas en este ámbito. Frente a los años ochenta y noventa del siglo, que bien pudieran ser considerados una suerte de edad dorada de la gestión pública, los primero años del siglo XXI en general y los de la crisis en particular parecen haber constituido una suerte de década perdida para nuestroa estudios. No hay propuestas elaboradas de cambio de paradigma, ni siquiera parecen haber sido años relevantes para las recurrentes modas de gestión, ni tampoco han brillado gurus al estilo de Osborne, Gaebler o Hammer. Tampoco han aparecido grandes documentos oficiales de reforma admnistrativa al estilo del célebre, pero ya pasado de moda, informe Gore. Un poco de gobernanza, combinado con algo de estudios de redes y coordinación y otro poco de partenariados público-privados y transparencia, parecen haber sido el magro legado de estos años de escasez y austeridad. Sólo parecen haber revivido un poco las viejas teorías de la gestión del recorte y el decrementalismo en desuso desde las crisis de los años setenta y algún tímido intento de recuperar el estudio de las teorías sobre priorización del gasto público. Pero aún así el repaso de las propuesta de reforma en la administración y la gestión pública nos aportan dos grandes enseñanzas, que se pueden deducir de la lectura de este libro aunque no se manifiesten expresamente, la que la reforma administrativa no es válida para tiempos de austeridad, pues normalmente implica a corto plazo el gasto de recursos, precisamente en tiempos en que estos no abundan, para obtener resultados, que en el caso de obtenerse lo serían a largo plazo. La segunda es la enorme influencia que siguen conservando las tradiciones administrativas nacionales, y que son bien analizadas en los apéndices del libro. B. Guy Peters editó hace poco un libro sobre la influencia de la tradición administrativa a la hora de confrontar reformas y cambios en su funcionamiento, y como el querer introducir reformas ambiciosas que alteren dicha tradición están sistemáticamente condenadas al fracaso. Es difícil, por ejemplo, introducir elementos de una tradición gerencialista como la anglosajona en administraciones burocrática de tipo napoléonico mucho más rígidad y garantistas. Las reformas 
administrativas, y esto es una lección que debemos aprender de esta crisis deben ser planteadas dentro de su propia tradición bajo el riesgo de caer en la irrelevancia.

Son estos dos aspectos los que constituyen el núcleo del libro. En este están presentes y se analizan las principales tradiciones administrativas occidentales, la anglosajona, la continental o de estado de derecho y la napoléonica a las que suma como complementos las tradiciones nórdica y las diversas tradiciones de la antigua Europa del Este. También dedica un apartado especial a la incipiente administración de la Unión Europea, que comienza a ser estudiada como una nueva tradición administrativa, que lentamente va impregnada a las distintas tradiciones nacionales. Los autores elaboran también una interesante metodología de comparación de tradiciones en las que se analizan desde aspectos puramente políticos, como la forma del gobierno (monocolor o de consenso) o el tipo de relaciones entre los políticos y sus gabinetes de asesores, hasta aspectos netamente administrativos, como la organización administrativa. Y por supuesto analizando las interacciones de ambos, concretadas en las formas de gobernanza gobierno-burocracia y las distintas tradiciones de filosofía política de cada país. El libro cuenta incluso con un detallado apéndice donde se analiza la evolución de las reformas administrativas en muchos de los países de nuestro entorno políticoadministrativo.

Pero es sin duda la parte final del libro, los tres últimos capítulos, donde se desarrolla a mi entender un análisis más profundo de las experiencias de reforma. Si bien la primera parte realiza una detallada descripción de los procesos s en la segunda parte donde brilla más su intuición politológica. Es aquí donde se discuten los cambios en las relaciones de poder entre políticos y burócratas acontecidas depués de las reformas en los años de la gran austeridad. Lo primero que se preguntan los autores es si esta relación ha cambiado, y la respuesta es que si bien esta varía entre los distintos países, todo apunta es que quien más ha ganado en estos años son los políticos. Aparentemente con las reformas los burócratas han ganado en discrecionalidad y capacidad de gestión, pero los políticos en cambio han ganado primero en capacidad de intervención, al incrementar al mismo tiempo sus poderes de auditoria y control y, con la crisis, su capacidad de asignar recursos a las distintas admnistraciones. Con este sistema la capacidad de los políticos de incrementar su poder de patronazgo se ha reforzado, pues la discreción a la hora de nombrar a los altos cargos de la administración es ahora mucho más manifiesta de lo que era hace no tanto tiempo.

Como dirían los chinos, la crisis se ha transformado en una excelente opoertunidad de ganar poder de decisión a costa de los burocratas que en cambio se han visto presionados a hacer más con menos asumiendo incluso responsabilidades de las que se liberar los políticos. Si bien la línea de demarcación entre política y administración no parece haberse movido mucho si puede percibirse en general cierta pérdida de peso de esta última. Hay, sin embargo, un aspecto al respecto que nuestros autores no parecen haber considerado con la importancia que tiene y es el de la irrupción, al menos en Europa, de un nuevo actor, el de la administración de la Unión Europea. Si bien el poder de los burócratas de los estados nacionales europeos parece estar en retroceso, no así el de las burocracias europeas, como ocurre, por ejemplo, con el Banco Central Europeo que parece haber reforzado su poder en los años de la crisis. El debate sería determinar si tales instituciones pueden ser contadas en el ámbito de los burócratas o de los políticos, algo que no está claro aún. Como tampoco está claro si los componentes de la clases políticas de muchos de los países estudiados son políticos o burócratas. B. Guy Peters publicó hace años un gran libro, llamado La política de la burocracia en el que se describen los rasgos de lo que eñl denomina un gobierno burocrático. En este modelo de gobierno buena parte de los puestos y la mayor parte de las decisiones siguen normas y patrones de corte burocrático-administrativo, por lo que no se puede establecer una línea clara de demarcación entre unos y otros. Es cierto que este modelo sólo se da en algunos entornos concretos y con diversa intensidad, pero en países como el nuestro es una realidad evidente. Sólo hay que observar cual es la extracción profesional de los gobernantes en España o en los países de nuestro entorno más inmediato para comprobarlo. No sólo burócratas, normalmente de alto nivel, pueblan los consejos de ministros y los puestos altos del escalafón sino que su lógica de funcionamiento sigue más los patrones propios de la administración que los de la política de partido. Después de este análisis de las relaciones entre política y administración entramos en la que, si cabe, es la parte más interesante e imaginativa del libro. Muchos libros de esta temática reservan los primeros capítulos a exponer su teorías y principales aportaciones y dejan para los capítulos finales los estudios de caso y los datos estadísticos. En este trabajo, en cambio se reserva para la parte final la esencia destilada de sus mejores argumentos. En la línea de los justamente célebres proverbios de la administración de Herbert Simon los autores exponen una serie de contradicciones o trade-offs en el discurso de la reforma administrativa, y al igual que él denuncian la banalidad de buena parte de los textos, en especial los docu- 
mentos oficiales, relativos a esta disciplina. Los autores distinguen ocho contradicciones principales, pero me gustaría aquí discutir sólo un par de ellas.

La primera de ellas es lacontradicción que encuentran los autores en los discursos teóricos de la nueva gestión pública es que pretende a la vez incrementar la capacidad de control de los políticos sobre la administración, al tiempo que pretende dotar a los responsables administrativos de mayor autonomía de gestión y todo ello combinado con una mayor implicación del ciudaano en la prestación de los servicios públicos. Por separado todas parecen muy loables. Parece lógico por una parte un mayor control del funcionamiento de las agencias públicas por parte de instituciones electas de forma democrática como parlamentos y ejecutivos para evitar mandarinatos y la captura de las instituciones por parte de los gobiernos. También parece razonable permitir al gestor administrativo una mayor autonomía en el desempeño de sus funciones. Un excesivo control por parte de actores poco informados acerca de las necesidades o los procesos de la agencia sólo puede contribuir a un peor desempeño o a una ralentización innecesaria del funcionamiento de la agencia. Y como no, ¿quién podría oponerse a establecer formas de participación ciudadana o de los colectivos implicados o afectados por el discurrir diario de una unidad administrativa? Los teóricos de la calidad total o de la reinvención del gobierno han incidido mucho en este aspecto y es de general observancia esta creencia entre los principales teóricos de nuestro ramo. Lo lógico sería entonces establecer algún tipo de jurado o comisión ciudadana que implique a todos los actores afectados.

Pero como se puede percibir, a poco que se analice, es que las tres propuestas se anulan mutuamente y no pueden ser aplicadas a un tiempo sin alterar gravemente los resultados de la actuación administrativa. Una mayor participación ciudadana y un control democrático por parte de los ejecutivos son en muchas veces incompatibles entre sí, pues operan dos lógicas democráticas en conflicto. Además ambas son incompatibles con una mayor autonomía en la gestión pública. El gestor se vería abrumado en su labor por demandas, ambas muy legítimas, provenientes del gobierno y de la ciudadanía y que no tienen porque ser coherentes entre sí. Pueden ser muy legítimas tales demandas, pero creo que se puede coincidir en que estas limitan, no aumentan la autonomía del gerente.

La otra gran contradicción la tenemos muy presente en nuestro país en temas como el de las pensiones de jubilación. La retórica de la reforma pretende por un lado fomentar la innovación mientras que al mismo tiempo pretende mantener unas políticas públicas predecibles, que incrementen la confianza en sus respectivos gobiernos. Muchos gobiernos, entre ellos el nuestro han emprendido ambiciosas reformas en los sistemas de pensiones o cobertura de desempleoen los años de la crisis, ejecutando propuestas muy innovadaras e imaginativas, con la idea en mente de mantener de una forma u otra los rasgos esenciales de un sistema público de previsión. Pero esta principio de continuidad ha alterado sustancialmente las expectativas de millones de ciudadanos que han visto afectados sus planes y expectativas de vida por culpa de estas reformas. Estas innovaciones pueden garantizar a medio plazo la pervivencia del sistema pero paradojicamente han modificado la percepción que estos ciudadanos tienen de su gobiernos, al aparecer estos como entes no merecedores de confianza e incluso como explicitamente mentirosos. La innovación en la gestión puede ser un objetivo muy recomendable pero entra en muchas veces en contradicción con la pretensión de incrementar la confianza y la predicibilidad de las instituciones.

Sirvan estos dos ejemplos de contradicciones para animar a la lectura de este libro, pues en una reseña de este tipo no podemos extendernos más. Sólo queda lamentar que en el libro no se aborde más que superficialmente, y en el marco de las administraciones napoléonicas, el estudio de las experiencias de reforma hispanas, bien porque los autores no las conozcan, bien porque estas no se hayan desarrollado con la amplitud necesaria como para justificar su estudio (me temo que esta pueda ser la explicación más correcta). De ser así este libro tendría que ser inmediatamente traducido pues creo que sería una gran aportación académica para nuestros estudiantes y ayudaría a nuestros políticos y burócratas patrios a entender las complejidades te'cnicas y políticas de los procesos de reforma en la gestión pública. 